\title{
A case for adapting and applying continuance theory to education: Understanding the role of student feedback in motivating teachers to persist with including digital technologies in learning.
}

\section{DR NOELINE WRIGHT}

THE UNIVERSITY OF WAIKATO

\begin{abstract}
In New Zealand schools, the adoption and persistent use of digital tools to aid learning is a growing but uneven, trend, often linked to the practices of early adopters and/or robust wifi infrastructure. The Technology Adoption Model is used internationally to gauge levels of uptake of technological tools, particularly in commerce and also in education. However, this model is inadequate when it is used to attribute reasons for teachers adopting technologies for learning. This article offers an alternative view to understanding why teachers continue using digital technologies for learning. It focuses on the role of student voice and teachers' pedagogical purposes as motivators, even when teachers have technological hurdles to overcome. The article engages with continuance theory as a lens for understanding these motivations via a qualitative thematic analysis of Moodle postings made by a 2012 cohort of initial teacher education students. The intention is to signpost ideas that might better explain teachers' continued use of digital technologies in classrooms even if conditions for use are not optimal.
\end{abstract}

Keywords: initial teacher education, pedagogy, secondary schools, teaching, continuance theory, digital technologies, ICT.

\section{Introduction}

\section{New Zealand context}

The provision and uptake of digital technologies (including mobile devices like smartphones and tablets) in New Zealand schools is patchy and idiosyncratic because local contexts and self-governance have such an influence in what counts as important in individual schools. This variation includes the degree of importance a principal and Board of Trustees (a school's governing body) attaches to the provision of robust wifi and up-to-date digital tools. Increasingly, more and more schools are opting for such provisions including students and teachers being encouraged to bring and use their own mobile devices. This is described as 
either BYOD (bring your own device), or BYOB (bring your own browser). On the other hand, some principals still harbour reservations about the potential links between mobile digital technologies and learning. For example, in a newspaper article describing some recommendations from the Education and Science Committee's report to parliament ${ }^{1}$, one principal "said she had no plans to introduce a compulsory device policy. 'I don't feel that it's a critical need for students to have one to use to learn effectively"' (Carson, 19/01/2013). Perhaps this attitude indicates something of the ambivalence some secondary school leaders have about the rapid rise of personal mobile devices, even while a growing number of schools are moving to integrate these technologies into everyday practices.

In New Zealand schools, therefore, the adoption and persistent use of digital tools to aid learning is a growing but uneven trend, often linked to the enthusiasm and practices of early adopters perhaps taking advantage of, or successfully lobbying for, a robust wifi infrastructure. When school leaders actively support robust wifi provision and technological support while encouraging staff and students to use mobile digital devices, then continued, persistent use within individual teachers' classrooms is more likely. This article argues that in New Zealand schools, teachers' continued use of any innovation is most likely predicated on their impact on learning. This article examines that assumption in relation to initial teacher education students' motivations as a signpost for continued use of digital technologies once these pre-service teachers have their own classes.

To begin with, international studies are examined, and the basis on which they argue their conclusions, followed by some examples in New Zealand to further contextualise the focus of this article.

\section{Relevant international studies}

Aldunate and Nussbaum (2013) examined the trajectory of teachers in Chile in their use of specific technologies. These technologies were an education web portal, digital cameras and smartboards. Aldunate and Nussbaum used the Technology Adoption Model as the methodological lens by conducting a survey centred on teachers' views of the ease of use of these technologies. They then extrapolated that those who continued to use them were most likely those who self-identified as early adopters of technology. This extrapolation links directly to the Technology Adoption Model which focuses on the extent to which the technologies are easy to use and support the efficient completion of tasks. Their study did not account for teachers' pedagogical purposes in using the devices. There was also no mention of how students responded to learning when teachers used the technologies, nor whether their responses influenced teachers' continued technological use. Understanding these two elements, I argue, are more illustrative of what motivates teachers to innovate with technological tools than a Technology Adoption Model. This is because the Technology Adoption Model broadly serves to categorise rates and kinds of adoption, but doesn't necessarily help us understand factors which drive particular kinds of adoption in educational contexts.

It is necessary to better understand why teachers persist with digital technologies, even when local conditions in a school are not ideal. A theory normally applied to business

\footnotetext{
${ }^{1}$ Inquiry into 21st century learning environments and digital literacy (I.2A) (19 December 2012) http://www.parliament.nz/en-NZ/PB/SC/Documents/Reports/7/e/2/50DBSCH_SCR5695_1-Inquiry-into-21st-centu ry-learning-environments.htm
} 
contexts, continuance theory, might be useful here. Continuance theory - different from the Technology Adoption Model used to inform the Chilean study Aldunate and Nussbaum (2013) undertook - grew from examining why staff and customers of a bank would continue to use specific online technologies (Bhattacherjee, 2001). Bhattacherjee was interested in cognitive beliefs and affect in those expected to use specific information systems to complete tasks for the bank in a United States setting. Through survey instruments, he determined that users would continue with the online information system if they were satisfied that it was fit for purpose and was more efficient at getting the job done than other processes. In this respect, it links to the Technology Adoption Model.

Sørebø, Halvari, Gulli and Kristiansen (2009) also considered continuance theory, but this time in an educational context in Norway. They were interested in teachers' extrinsic and intrinsic motivation plus self-determination. In other words, it was an attempt to establish teachers' degrees of professional agency in using digital technologies (Pachler et al, 2010). Sørebø et al argued that, 'It is therefore plausible to believe that teachers' lack of willingness to utilize e-learning possibilities beyond the initial adoption stage may lead to underutilization by students, and hence, in the next instance this may leads to reduced learning outcomes' (p. 1177). This rather negative conclusion highlights what may be at stake for some learners' potential educational outcomes.

While there is the potential to query the implied cause and effect intimated in the Sørebø et al (2009) quote, my article has a different focus - about teachers' persistent, continued use of digital technologies and possible reasons for this. Sørebø et al (2009) used a mail questionnaire distributed to university lecturers who identified as using the organisation's e-learning system. They were attempting to learn more about lecturers' continuance intentions by adapting an existing Basic Need Satisfaction at Work Scale. This questionnaire included predetermined options for respondents to choose from when they answered it. This raises potential issues in terms of leading respondents' answers, or possibly restricting opportunities for divergent views or perspectives. And this study, based in a tertiary education context, does not help understand school sector educators' reasons for continuing to use digital technologies for learning.

Roca, Chiu and Martinez (2006) also used surveys of respondents. They wanted to map aspects of satisfaction, perceived usefulness and ease of use of a specific e-learning system in Spain. Their respondents were direct users of an LMS in another adult learning context, and discovered that ease of use was the most common factor in participants' continued use of it. However, this study was also not directly related to teachers' continued use in schooling sectors, and so while Roca, Chiu and Martinez (2006) extended Bhattacherjee's (2001) framework in relation to the Technology Adoption Model and continuance theory, their findings are of limited use to my focus on teachers' use.

Aldunate and Nussbaum (2013) used the Technology Adoption Model as a means of understanding teachers' dispositions regarding technology use in their classrooms. This related to both the kinds of technologies they used, and their attitudes to such innovations. This focus meant Aldunate and Nussbaum excluded any mention of, or attention to, the pedagogical purposes teachers had for using these technological tools. There was also no space to address feedback from learners about the value of this technology use to their learning. Lastly, the kinds of technologies examined were specific, limited, and used by the teachers only - there was no mention of any student engagement with using them.

Another investigation into teachers' adoption and integration of technology into 
classrooms in the United States (Inan \& Lowther, 2010) described it in three ways:

'technology for instructional preparation, technology for instructional delivery, and technology as a learning tool' (p. 138). By using a path analysis statistical method approach, the authors assert that they showed links between variables and demonstrated causal relationships.

However, the listed variables were both teacher-centric and institution-centric (such as years of teaching, computer proficiency, technical support, computer availability). Any effects on learners, or what learners had to say about teachers designing learning with these tools tended to be overlooked. What was also overlooked was any focus on pedagogical practices, and if these were affected by any incorporation of digital technologies. This contrasts markedly with Orlando's (2013) longitudinal examination of the effects on teachers' pedagogies and thinking when ICTs inveigled themselves into teachers' everyday professional practice in Australian educational contexts.

Laugeson (2012) has created a meta-analysis of 75 quantitative studies about continuance theory. At one point, he notes that there appeared to be three categories of studies: personal. educational, and corporate. He suggested that education in particular appeared to have "vigorously adopted ISC theory to study e-Learning" (p. 11). He accounts for it by suggesting that "Personal and Educational IS [information systems] use is most likely voluntary and therefore confirmed expectations would be expected to have a strong relationship with satisfaction, perceived usefulness and intention to continue using the system" (Laugeson, 2012, p. 11). However, he does not indicate why he believes the information systems use is voluntary, or why this voluntary aspect is a strong link to satisfaction. After all, in education, teachers are most likely to experiment with tools and systems in order to see what works for learning. The idea of 'satisfaction' is, I argue, based on more than the teacher's use of the tool, but is more likely to relate to their desire to see positive outcomes for learners. These positive outcomes may manifest themselves in behaviours such as increased concentration, better work quality, and greater thoughtful collaboration on tasks.

Unlike Orlando, both Inan and Lowther (2010) and Aldunate and Nussbaum (2013) separate teachers from their learners in their studies. This separation is echoed in earlier work by Levin and Wadmany (2008), who followed three primary school teachers for three years in Israel, seeking to understand their thinking and practices while integrating technologies into their classroom practices. However, there was very little mention of student learning or if any of their feedback was elicited when new technologies were being used. There was also no suggestion that students' feedback, if sought, influenced teachers' thinking and practices when designing learning with digital tools. There is thus a pattern in these authors' works of centring attention on understanding teachers' adoption practices while excluding the perspectives of learners about the potential benefits to learning. Orlando's work, in contrast, elicited student feedback via focus group interviews, but did not, as a rule, expect teachers themselves to seek this feedback. This article, however, suggests that this is a critical element for teachers' decision-making regarding using technological tools in their classrooms.

\section{New Zealand studies}

In New Zealand a few case studies suggest an approach to understanding what motivates teachers to experiment with, and continue to use, digital technologies in their classrooms. One such example suggested that continuance theory and a socio-cultural ecology theory 
could help in understanding mobile technology adoption in secondary school classrooms through examining practices in one school. This school trialled a BYOD approach to learning that included students creating their own artefacts of learning that were stored on their phones or other mobile device as short movies. The report noted that:

Evidence points to students' agency and repeated use when it helps them learn and when they can create digital learning products. Also, teachers engaged in the study remarked on observing positive changes in students' learning behaviours when using digital tools (such as greater focus and concentration, task completion and, therefore, engagement), and this led to teachers as well as students, becoming keen to continue using these technologies/tools and expanding their use (Wright, 2012a, p. 2).

Perhaps other secondary school teachers beyond this school are likely to be motivated to alter their professional practices by adapting and appropriating resources or tools when they perceive that through their use, the is a positive impact on student learning. Continued and persistent use is therefore more likely to be predicated on more than the ease of use that the Technology Adoption Model suggests: it is bound up in how students respond to learning with and through using digital tools. This links to the socio-cultural ecological view regarding young people's uses of digital technologies as espoused by Pachler et al (2010).

However, using digital technologies in lessons, especially when a school's infrastructure is creaky or indifferent to this, is not straightforward. Persistence in the face of obstacles (such as: firewalls; old or slow equipment; poor broadband; booking, collecting, using and returning shared equipment; or uncertain technical assistance) or isolation (for example, being the only one in a department experimenting with digital technologies) is important to understand. Such impediments feature in a number of schools, as principals and teachers struggle to adapt to a technologically mobile and wired school populace. Persistence in education contexts therefore goes beyond what a continuum like the Technology Adoption Model can offer. Persistence and continuance also suggest that for teachers, at least in New Zealand, their motivations are more complex than authors such as Aldunate and Nussbaum (2013), Sørebø et al (2009), Inan and Lowther (2010), Roca et al (2006), or Levin and Wadmany (2008) suggest.

What follows is how evidence from an initial teacher education context is used to discuss the value of student feedback to teachers when digital technologies are used in lessons.In turn, this supports my contention about continuance theory in education contexts.

\section{Context of study}

The investigation described here sought to address the question: What characterises initial teacher education students' (pre-service teachers) experiences of using Teaching as Inquiry to investigate the value to learning of incorporating a digital tool/technology in a specific lesson?

\section{Initial teacher education}

Initial teacher education (ITE) students in the secondary graduate programme undertake two practica (approximately six and seven weeks) in two different New Zealand secondary schools. Their reported experiences provide the basis for arguments raised in this article, 
which approaches the data in a slightly different way from the initial research question in order to focus on what motivated these pre-service teachers to continue using digital technologies for learning. This is thus a qualitative investigation that examines existing data with a continuance theory lens.

As noted earlier, New Zealand schools are described as self-managing, contributing to wide variety in school contexts and cultures - including the leadership style of the principal, the ethnic and socio-economic demographics of schools and the level of commitment to a robust digital technology infrastructure. This latter includes the degree of access to mobile devices and robust wifi access. When pre-service teachers go on practicum, their experiences are affected by this variation of digital provision and the extent of their access to it in schools. This article therefore explores ideas about why these pre-service teachers would bother again with digital technologies. What motivated them to keep using them?

\section{Cohort and methods}

The 2012 cohort in the one-year graduate teacher education programme consisted of representations of almost every subject area within the New Zealand Curriculum. These subjects include English, Maori, foreign languages (such as French, Spanish, German), technology subjects (hard materials, soft materials, computer studies, graphic design), arts (music, fine arts, drama), social sciences, mathematics, sciences, physical education and health. During their practicum, the cohort were required to incorporate a digital technology into a lesson, examine its use in relation to a Teaching as Inquiry question, and ask students for their feedback on their learning. Moodle, the LMS, was used as the receptacle for posting their feedback on this task. This feedback was also available to each other to learn from. The Moodle postings about the individual reports became the main data set for analysis.

Ethical consent for using their Moodle postings after their practicum experiences as research data was obtained through a message posted within this LMS, requesting them to identify either their consent or refusal to allow their posts to be used as research data. Out of a cohort of 80 , there was one refusal. The posted data about two practicum lessons at two different times of the year were downloaded from Moodle and printed once the programme had finished. The data consisted of over 300 pages of text, forming a collection of diverse experiences, subject areas and reflections.

The Teaching as Inquiry process used for this task is adapted from the New Zealand Curriculum (Ministry of Education, 2007), and is explained more fully at http://bit.ly/Wlobo5 . Essentially, the cohort were expected to construct a question about a puzzle of practice related to incorporating a digital technology or affordance into at least one lesson. In this lesson to formally report on, the pre-service teachers were required to describe the context (class, level, topic, subject), the digital tool they used and why, what happened in the lesson, how they elicited feedback from their learners (including the questions they asked and samples of the feedback), what their associate teachers thought, and their conclusions and reflections after analysing their data. They also had to explain how this informed what (and if) they would use such tools or affordances again, and why. Lastly, they had to explain the extent to which they could answer their own Teaching as Inquiry question (Wright, 2012b), producing thick descriptions of practice. Because the task had required them to include in their lesson a deliberately designed method for seeking student feedback, the task addressed one of the shortcomings (not taking into account one's learners) already noted in 
Aldunate and Nussbaum's (2013) study findings.

\section{Analysis}

A qualitative thematic data analysis process took place once the pre-service teachers had completed their programme and were thus no longer involved in any assessments for the course. The analysis built on notes jotted during the task assessment. These notes consisted of listing items like the tools the pre-service teachers used and their names if their experiences could usefully illustrate particular themes of appropriation and/or persistence. From this initial set of notes, frequency coding and thematic analysis created a more finely grained interrogation of the Moodle posts. A spreadsheet was also used to itemise the tools, contexts, year levels, and the stated pedagogical purposes for using specific digital tools. This spreadsheet was then sorted in various combinations, such as by tools, subjects or purposes. This sorting process made it easier to see how different combinations of items could affect how I 'saw' and coded the data. This process of noticing, thinking and collecting echoes Seidel's (1998) view of how qualitative data analysis take place. It also exemplifies the idea of reflexive interaction which Srivastava and Hopwood (2009) say are "at the heart of visiting and revisiting the data and connecting them with emerging insights, progressively leading to refined focus and understandings" (p. 76).

Comparisons were also made with what the pre-service teachers reported what their learners said about the lesson and the value of the technology to the learning process. In a sense, this process is a qualitative content analysis, a relatively common method in situations where written text is under examination. Lankshear and Knobel (2004), for example, used this method to examine written responses in a qualitative survey.

The qualitative data analysis process was thus modelled on Seidel and Kelle's (1995) and Seidel's(1998) advice. It allowed the data to be examined both deductively (in relation to continuance theory) and inductively (letting themes emerge from the data). I argue that this process mirrors what Orlando (2013) described when analysing her data generated from a five-year investigation. Her process "included multiple acts of design, comparison, dialogue, reflexive critique and interpretation which helped to understand and explain the teachers' ICT practices, rather than to evaluate their actions against firm criteria" (p. 236). In other words, the reflexive critique and comparison of the data across the pre-service teachers' experiences helped distill themes. Had there been "firm criteria" against which the data should have been evaluated, I may not have noticed the key ideas relevant to this article.

A selection of findings is used to illustrate the influence of students' feedback to the initial teacher education teachers when they are asked about the value of using digital technologies to help them learn.

\section{Findings}

The pre-service teachers used a wide range of tools which they repurposed for specific learning contexts, which were as varied as the tools they chose. For example, one fine arts ITE student appropriated the game Angry Birds for a year 9 class (approximately 13 year olds). They were instructed to play it as a precursor to examining the characteristics of the angry birds for a sculpture-making assignment. The task required them to assign these defined characteristics to New Zealand birds (Manu Riri). As the pre-service teacher noted, 'The [learners] discussed the characters as a group and in pairs and [then designed] their 
own 'angry birds'...narrative around New Zealand native birds' before creating papier mache versions of their chosen bird. This task involved learners in applying analysis, transference, reflection and synthesis, as well as peer interaction and collaboration. During the unit, the ITE student observed high levels of engagement (cognitively, behaviourally, and affectively), learning-focused talk and task completion. The appropriation of this Angry Birds game for learning in a fine arts context was related to well-defined learning objectives, intending to harness imagination and creativity. The response of the students to the task encouraged the pre-service teacher to think about 'how [he's] going to adapt this task next time - [he] might try a different model and hope the kids respond as well as these ones did'.

There were other examples of creative appropriation. One science ITE student for example, created a webquest on ecology, another used a Java applet for helping learners understand a physics principle. In a senior Food and Nutrition class for physical education, learners were required to calculate a budget for a nutritious family dinner by using a supermarket chain's online store site or App. In art and design, learners were encouraged to use Pinterest to collect examples of artists' models and design ideas for later critique, while in an English class, learners used the camera function on their phones to take images for later use as writing stimuli. Other learners videoed themselves with their own devices as they rehearsed Kapa Haka ${ }^{2}$ moves at home, thus having an artefact of their rehearsal to evaluate for themselves, critiquing their own skills and performance level before explaining their reflections to the pre-service teacher and/or their peers the next day.

These examples demonstrate that the pre-service teachers not only adapted to the practicum school's existing provisions and policies about digital technologies, but also created opportunities for learners to experiment with learning mediated by digital technologies. Perhaps this accounts for the diversity of purpose and tools used on practicum, leading to some imaginative pedagogical design. Features of design included the articulation of the thinking skills they were trying to foster in their learners, and the student-centric, agentic nature of the learning tasks.

When they reviewed their learners' feedback on the lesson(s), the pre-service teachers were encouraged by the positive comments when the technology worked in their favour. For example, they remarked on how much simpler it was to understand difficult, abstract or complex concepts when digital technologies made access to the learning easier, often through visual and manipulable representations they had access to themselves. Other factors included learners' sense of efficacy in creating better-looking products of learning, or being able to find answers faster than they might otherwise have done. The dynamic nature of using digital technologies was a demonstrably strong hook into learning, especially if the learners themselves were using the digital technologies. This was a noticeable thematic thread in the data.

The pre-service teachers consistently commented on how encouraging their learners' feedback was, and how closely this linked to their statements about wanting to repeat similar lessons with similar tools in the future, since they had evidence of positive effects. These effects were greater than expected: they linked to deep concentration on tasks, greater collaboration across groups of students, the sharing of peer expertise and problem-solving, and the desire to keep on task beyond bell times.

Initially, many pre-service teachers had been hesitant and nervous about deliberately

\footnotetext{
${ }^{2}$ Maori performing arts
} 
collecting feedback from their learners. They often admitted that they felt awkward and vulnerable in doing so. But, as Hattie and Timperley (2007) argue, feedback is a crucial element for learning; it is also true for pre-service teachers who must learn how to reflect on their own pedagogical practices when integrating digital technologies into lessons. Seeking feedback from their learners in such contexts meant they had documented evidence for their decision-making about questions such as:

- Does using this tool make a positive difference to understanding [a particular concept/concept]?

- What advice do my learners suggest about this lesson?

- Is this tool fit for the learning purpose?

- Is my pedagogical design of the lesson appropriate?

When things went wrong - and they often did- (such as firewalls blocking access, servers being down, slow bandwidth, slow or old machines) their learners were scathing - but mostly of the school's technology provision, rather than what the ITE student had tried to facilitate. This distinction is significant, for learners were keen to learn with and through these digital tools, but felt thwarted and frustrated by inefficient or creaky school tools.

But even when the technology went awry, pre-service teachers had plenty to learn. This is why I had impressed on them that the lesson didn't have to be a success to fulfil the task I set, since their reflections and analysis of their students' feedback were more important. Being able to articulate their learning about how to overcome such issues again, was much more interesting to read about, and important for their professional learning. In their reports on practice, the pre-service teachers therefore detailed what they discovered about preparation for the smooth running of their class in a technological sense (and, often, in a behaviour management sense). These preparations included checking firewalls, bringing spare cables to connect between devices, checking that batteries on shared devices were charged, that the Internet/wifi was robust enough, and that they had a Plan B if something didn't work. Sometimes, this preparation included practising with a room's equipment, or shared devices or programs. It required experience for the pre-service teachers to understand the value of some forward thinking and and how to bias for success when using digital technologies.

However, preparing for digitally-enabled learning can easily add to a teacher's workload, so why would teachers bother, and why would pre-service teachers continue to bother if it becomes voluntary and not an assessed task? Essentially, the findings suggest that learning benefits have to outweigh the additional preparation effort before teachers were prepared to continue using these tools. Consistently, the message from the pre-service teachers was clear: if they saw that learners were more motivated, learned more easily, concentrated more, collaborated more and completed tasks to a higher standard than before, then they considered it was worth doing. The positive nature of the feedback from their learners thus helped the pre-service teachers make sense of not only the learning experiences, but also how the digital technologies enhanced learning, and helped them address their own puzzle of practice Teaching as Inquiry question. An added incentive was how they dynamics of the classroom altered in relation to the relationship between teacher and students, and among students.

\section{Discussion and conclusion}

These classroom experiences broadly taught the pre-service teachers that most of their 
students wanted their learning to be digitally mediated. Because of that, and because their learners behaved with greater motivation, engagement and task-oriented focus when using such tools, most of the pre-service teachers stated that they intended continuing to develop their proficiency with digital and mobile technologies in classrooms. They looked forward to taking on their own classes for this reason, but also began to ask about how to lobby for robust access to technologies - both for them and their students. This kind of questioning led to other teachable moments.

The practicum findings identifying specific effects on students' learning behaviours when digital technologies are used in classrooms raised here, corroborate findings from similar classroom-oriented investigations (Wright, 2012a). Like the teachers in Wright's (2010) mobile device case study, the pre-service teachers made decisions about the extent to which they would repeat any digital technology use. In every case, they were based on the value of the learning effect on their students.

Perhaps too, this siting of the investigation squarely in teachers' own practices was a powerful example of Mishra and Koehler's (2006) TPACK framework in action. In that model, Mishra and Koehler argue that teachers' digital competencies will develop only when they are in relation to, and in harmony with, their pedagogical and content knowledge. In other words, closely tied to their professional work. This resonates with a recent study centred on New Zealand pre-service teachers' experiments with ICT on practicum (Nordin, Morrow \& Davis, 2011). Together, the findings from both studies point to motivations for teachers continuing to use digital technologies that go beyond satisfaction with the tool or its ease of use for the teacher. Their motivations are situated with how their learners' attitudes to learning change, especially when they are the prime users of the technology.

Put another way, the socio-cultural ecology framework argued by Seipold and Pachler (2011) situates learners as key players in digital technology use, particularly if they are the creators of digital products of learning. For some pre-service teachers, seeing both themselves and their learners as having agency was an epiphany about teaching and learning, further motivating them to continue with using and trialling digital technologies.

In terms of applying continuance theory to education, digital technology adoption, repeated uses for learning, and understanding the value for learners are key factors for teachers. A Teaching as Inquiry method of investigation helps them know what this value is, especially when evidence about learners and learning is explicitly sought as part of the process of investigation. This is even more important to consider when pre-service teachers are still new to pedagogy, being in charge of classes of learners, and being novices at classroom management. And when a school's digital infrastructure is less than satisfactory and requires more teacher effort to leverage it, perceived benefits for learners are crucial in a teacher's determination to continue incorporating digital technologies as tools for and mediators of learning.

Experienced teachers (ie those teaching for over 10 years) as evidenced in Wright's (2010) evaluation of a school's experiments with using cellphones as learning tools, provide additional evidence for what teachers value. When teachers' pedagogy is secure, they are unlikely to mind the possibilities of experiencing the 'pain of failure' if technologies went awry. When students get so much out lessons that incorporate digital technologies, teachers can overlook the failures, and carry on. As Wright argues:

... teachers with long experience and service are regularly accused of being 
conservative and unwilling to experiment [with digital technologies]. However, in order to cope with the uncertainty, complexity and potential failure of experimenting with new technology and pedagogical practices, it is often this very experience that is a key to success: such teachers have the background to be able to adjust practices in order to cope with unexpected contingencies. While much younger teachers may already have the technological nous, they usually lack the pedagogical experiences these other teachers can draw on to retrieve the learning in the face of technological disasters. As one of the teachers put it, experience helps you "endure the pain of failure". (2010, p. 10)

This quote hints at something richer than the Technology Adoption Model can offer, even though this model is popular as a way of quantitatively measuring the use and adoption of technologies, particularly in workplaces. However, in education, any tool can be used if it has a learning value. Such values are motivators for teachers, rather than being positioned on a scale of adoption. Perhaps for teachers, a position on a scale is meaningless if it ignores student learning. Secure pedagogical knowledge also links to a teacher's willingness to experiment, and this links to the TPACK model. The desire to enhance learning experiences is a prime motivator for continuance - if digital tools help, then teachers will persist.

Perhaps too, the more intimate research methods of interviews and classroom observations used in Wright's (2010) study, for example, allowed findings to grow out of the experiences rather than link to predetermined criteria. Aldunate and Nussbaum (2013) is a case in point. They used a survey containing predetermined options for those completing it, including using Technology Adoption Model terminology. We do not know if these terms were familiar to all survey participant teachers and if it affected their responses. In fact, most research using the Technology Adoption Model is quantitative; it may reflect the very different emphases of education and business. One is more of a relationship between people with learning goals in mind, while the other can be described as transactional. A survey suits one method, but not another if authentic perceptions and points of view are valued.

In the pre-service teacher study described for this article, data were pre-service teachers' own ideas, reflections and observations of their teaching experiences with technologies in lessons of their own design. Embedded in these reflections were comments about the value of asking their learners about their learning. In this way, my data set are enriched by points of view Aldunate and Nussbaum (2013) could not access because they were left out. The extent to which these different methods account for different outcomes, however, is moot - perhaps the analysis lens (that is, the Technology Adoption Model cf continuance theory) was more pertinent to the conclusions that were drawn.

In essence, although methods for generating data were very different, Aldunate and Nussbaum and I looked at similar questions about what it takes for teachers (or lecturers) to use and continue to use digital technologies in their classrooms (face-to-face or online) to support learning. In examining pre-service teachers' experiences about what they identified as reasons to continue using digital technologies in learning contexts, overall, such conditions principally link to the value they perceive to their students' learning. So, while continuance theory arose from commercial contexts, I argue that it can be adapted and extended for educational purposes through examining teachers' motivations about why they continue to use these technologies in their classrooms.

This article argues therefore, that continued use is more about the satisfaction 
teachers gained from the evidence of positive learning outcomes (such as motivation, concentration, task completion, higher quality learning products, more accessible learning, satisfaction with learning....), rather than being about getting a job done as it might in commercial contexts where efficiency and ease of use often drive continued use. It is also much more than being about fitting teachers on an adoption model continuum. Such placement on a continuum is unlikely to inform us much about teachers' motivations, purposes, or pedagogical thinking.

Instead, there is greater resonance with the cognitive and affective domains Bhattacherjee (2001) was interested in, and goes further than Aldunate and Nussbaum's (2013) Technology Adoption Model perspective. A survey that offers options to choose from rather than space to comment, may also restrict participants, particularly if the survey instrument is entirely focused on single dimensions, such as the Technology Adoption Model or the Basic Needs Satisfaction at Work Scale. While these models and scales have their place, they fail to acknowledge complexities inherent in educational contexts, including the role students play in classrooms and their effects on teachers' thinking and practices.

By using as data the pre-service teacher-created reports on practice that included their learners' feedback to them, a much richer picture emerged of practice and reflection. It highlighted the importance of learners' perspectives to these pre-service teachers' thinking and decision-making about why or when they would use technological tools and what would lead to persistent, continued use. These findings also point to ways of conceptualising teachers' work, practices, and motivations when they use digital technologies in their classrooms, beyond blunt instruments which ignore students' responses to learning. Perhaps Craig's (2013) suggestions about novice teachers' professional identity formation in relation to "their best-loved selves" (p. 261) might offer ways of conceptualising this.

The findings indicate too, that continuance theory, when applied to educational settings, has to account for more than ease of use or efficiency in getting jobs done. Also, the findings confirm how valuable student feedback to teachers is, in motivating teachers to persist with and repeat using, specific digital technologies.

\section{Reference list}

Aldunate, R. \& Nussbaum, M. (2013). Teacher adoption of technology. Computers in Human Behavior, 29(3). pp. 519-524. Retrieved 02/04/13 from: http://www.sciencedirect.com/science/article/pii/S074756321200297X

Bhattacherjee, (2001) Understanding Information Systems continuance: An expectation-confirmation model. MIS Quarterly. 25(3) 351-370

Carson, J. (19/01/2013) iPads a must for schoolkids. Waikato Times. Retrieved 01/20/13 from:

http://www.stuff.co.nz/waikato-times/news/8197610/iPads-an-iMust-for-schoolkids

Craig, C. J. (2013) Teacher education and the best-loved self. Asia Pacific Journal of Education. 33(3) 261-272 10.1080/02188791.2013.788476

Hattie, J. \& Timperley, H. (2007) The power of feedback. Review of Educational Research. 77(1) 81-112 doi: 10.3102/003465430298487

Inan, F.A, \& Lowther, D. L. (2010). Factors affecting technology integration in K-12 classrooms: A path model. Educational Technology Research and Development, 58(2) 137-154 
Lankshear, C. \& Knobel, M. (2004). A handbook for teacher research. From design to implementation. Berkshire: Open University Press.

Laugeson, J. (2012). The role of confirmation in IS continuance theory: A comprehensive meta-analysis. Proceedings, International Conference on Information Systems, Orlando Florida, USA from December 16-19, 2012 manuscript: ICIS-0901-2012.R1. http://aisel.aisnet.org/icis2012/

Levin, T. \& Wadmany, R. (2008). Teachers' views on factors affecting effective integration of information technology in the classroom: Developmental scenery. Journal of Technology and Teacher Education, 16(2), 233-263. Retrieved 01/25/13 from: http://www.editlib.org/p/22950.

Ministry of Education (2007). The New Zealand Curriculum. Wellington, New Zealand. Ministry of Education.

Nordin, H., Morrow, D. \& Davis, N. (2011). Pre-service teachers' experience with ICT integration in secondary schools: A case study of one New Zealand context. In M. Koehler \& P. Mishra (Eds.), Proceedings of Society for Information Technology \& Teacher Education International Conference 2011 (pp. 3915-3920). Chesapeake, VA: AACE.

Orlando, J. (2013). ICT-mediated practice and constructivist practices: Is this still the best plan for teachers' uses of ICT? Technology, Pedagogy and Education. 22(2) 231-246 DOI: 10.1080/1475939X.2013.782702

Pachler, Norbert; Cook, John; Bachmair, Ben (2010). Appropriation of mobile cultural resources for learning. International Journal of Mobile and Blended Learning, 1(2) 1-21 DOI: 10.4018/jmbl.2010010101

Roca, J. C., Chiu. C-M., Martinez, F. J. (2006) Understanding e-learning continuance intention: An extension of the Technology Acceptance Model. International Journal of Human-Computer Studies 64(8),683-696 Retrieved 02/5/13 from http://dx.doi.org/10.1016/j.ijhcs.2006.01.003

Seipold, J. \& Pachler, N. (2011). Evaluating mobile learning practice: Towards a framework for analysis of user-generated contexts with reference to the socio-cultural ecology of mobile learning. In, Themenheft Nr. 19: Mobile Learning in Widening Contexts: Concepts and Cases ISSN 1424-3636 Retrieved 04/30/13 from: http://www.medienpaed.com/19/seipold1104.pdf

Seidel, J. \& Kelle, U. (1995). Different functions of coding in the analysis of textual data, In U. Kelle (Ed) Computer-Aided Qualitative Data Analysis: Theory, Methods and Practice. London: Sage.

Seidel, J. (1998). Qualitative Data Analysis. The Ethnograph v5 Manual, Appendix E. Retrieved 01/5/12 from: http://www.qualisresearch.com/ or http://www.engin.umich.edu/teaching/crltengin/engineering-education-research-reso urces/seidel-qualitative-data-analysis.pdf

Sørebø, Ø., Halvari, H., Gulli, V. F., \& Kristiansen, R. (2009). The role of self-determination theory in explaining teachers' motivation to continue to use e-learning technology. Computers \& Education, 53(4), 1177-1187. doi:10.1016/j.compedu.2009.06.001

Srivastava, P. \& Hopwood, N. (2009). A practical iterative framework for qualitative data analysis. International Journal of Qualitative Methods, 3(1) 76-84

Wright, N. (2010). mLearning Capability Pilot Project at Howick College. Retrieved 11/05/11 from: http://softwareforlearning.wikispaces.com/file/detail/HowickmLearn2010.pdf 
Wright, N. (2012a) Pedagogy, continuance theory and mobile devices: Findings from a New Zealand case study. Proceedings of the 11th International Conference on Mobile and Contextual Learning 2012 (mLearn 2012), Helsinki, Finland, October 16 -18, 2012. Edited by: Marcus Specht, Mike Sharples, Jari Multisilta. Published on CEUR-WS: 09-Jan-2013 Retrieved 04/30/13 from: http://ceur-ws.org/Vol-955/

Wright, N. (2012b). Teaching as Inquiry. Retrieved 03/15/13 from:

http://myportfolio.school.nz/user/noelinewright/teachingasinquiry 